This item was submitted to Loughborough's Research Repository by the author.

Items in Figshare are protected by copyright, with all rights reserved, unless otherwise indicated.

\title{
Inductive method for assessing the amount and orientation of steel fibers in concrete
}

PLEASE CITE THE PUBLISHED VERSION

https://doi.org/10.1617/s11527-012-9858-6

\section{PUBLISHER}

@ RILEM 2012. Published by Springer

\section{VERSION}

AM (Accepted Manuscript)

\section{PUBLISHER STATEMENT}

This work is made available according to the conditions of the Creative Commons Attribution-NonCommercialNoDerivatives 4.0 International (CC BY-NC-ND 4.0) licence. Full details of this licence are available at: https://creativecommons.org/licenses/by-nc-nd/4.0/

\section{LICENCE}

CC BY-NC-ND 4.0

\section{REPOSITORY RECORD}

Torrents, Josep M., Ana Blanco, Pablo Pujadas, Antonio Aguado, Pablo Juan-Garcia, and Miguel Angel Sanchez-Moragues. 2019. "Inductive Method for Assessing the Amount and Orientation of Steel Fibers in Concrete". figshare. https://hdl.handle.net/2134/32320. 


\title{
INDUCTIVE METHOD FOR ASSESSING THE AMOUNT AND ORIENTATION OF STEEL FIBERS IN CONCRETE
}

Josep M. Torrents, Ana Blanco, Pablo Pujadas, Antonio Aguado, Pablo Juan-García and

Miguel Ángel Sánchez-Moragues

Construction and Electronic Engineering Departments, Technical University of Catalonia, Campus Nord, C1 and C4 buildings, Jordi Girona, 1, 08034 Barcelona, Spain

josep.m.torrents@upc.edu

\begin{abstract}
Steel fibers are ferromagnetic and they have the property of altering the magnetic field around them. This paper discusses a method and gives a practical example to measure, nondestructively, the amount and orientation of fibers from cubic concrete specimens (150 mm). This is possible because the fibers affect inductance of a sensor (an inductive coil) that is wrapped around the specimen.
\end{abstract}

Keywords: non-destructive methods, magnetism, inductive method, steel fiber reinforced concrete (SFRC).

\section{INTRODUCTION}

The recent publication of regulations and instructions (Blanco et al. 2010) related to fiber reinforced concrete (FRC) caused a significant increase of the application of FRC for structural purposes in the last years (Lambrechts 2008, Serna et al., 2009 and Pujadas et al. 2011). This increase should be accompanied by control methods with regards to the fiber content or the orientation of fibers that combine reliability and economy.

Several techniques have been applied to determine the dosage and/or orientation of the fibers in FRC, which can be classified as either destructive or non-destructive, and are based on direct or indirect measuring. Among the destructive measures, the most common method is the manual counting of the fibers after crushing the specimen (Soroushian and Lee, 1990; Gettu et al., 2005; Dupont and Vandewalle, 2005). With regard to orientation, Krenchel, (1975) proposed a method to determine the average orientation of the fibers in the cross section by means of a theoretical expression. Since the mean orientation of the fibers is proportional to the post-cracking strength of the steel fiber reinforced concrete (SFRC), several researchers have indirectly assessed the orientation of fibers by means of mechanical tests (Kooiman, 2000; Barragán, 2002; Grünewald, 2004).

Direct measurements about the orientation of a fiber can be obtained through such techniques as image analysis (Grünewald, 2004; Lappa, 2007), X-ray methods (Van Gysel, 2000; Robins et al., 2003; Vandewalle et al., 2008) or computerized tomography (CT-scans) (Molins et al., 2008; Stälhi and van Mier, 2007).

Recently, significant advances have been obtained with regards to the development of non-destructive methods for determining the orientation of steel fibers in elements on a large scale. These methods have to be previously calibrated on smaller samples. Examples of such methods are the alternating-current impedance spectroscopy (AC-IS) (Ozyurt et al., 
2006; Ferrara et al., 2008), the assessment of the electromagnetic wave reflection of microwaves produced in a coaxial transmission line terminated with an open circuit, acting as a sensor, and in contact with FRC (Torrents et al., 2009; Van Damme et al., 2004), the waveguide antenna (Roqueta et al., 2009), methods based on the electric resistivity (Lataste et al., 2008) and magnetic methods (Faifer et al., 2010). These methods enable easy and economic measurements of the orientation of fibers and have as a great advantage the fact that the uncertainties which tend to exist between the small-scale elements and the largescale ones, due to the different orientation of fibers in elements with different dimensions, can be avoided. These uncertainties appear when the measures obtained with a method addressed for small-scale elements are extrapolated to a full-scale structure without accounting for the differences in fiber orientation. More details about the methods and research related to the electric properties of concrete with fibers can be found in (ACI544.5R-10).

With regard to the control of the amount of fibers, regulations have been proposed for both fresh and hardened concrete [EN 14721:2005 and EN 14721+A1:2007, UNE-EN 14721:2001+A1:2008]. Both tests present considerable disadvantages with regard to costs, time and/or environmental issues. In the case of fresh concrete, a fresh mass of concrete must be washed (which requires high amounts of water and time) in order to separate the fibers by means of a magnet; and in the case of hardened concrete, the specimen must be crushed to, likewise, separate the fibers.

For the case of hardened concrete, the Spanish regulation UNE 83512:2005 proposes an alternative testing technique by means of magnetic methods which does not require crushing the specimen, with its corresponding advantages. However, this method has gone unnoticed and its use has not been widespread nor any practical testing method has been developed according to it. Besides, this methodology is absent in the updated version of this Spanish regulation.

Several explanations could account for this issue, but they are not fundamental to this paper, therefore only the advances in this direction will be explained. First of all, the magnetic method requires equipment with magnetic coils. The application of a magnetic field in a structure made of concrete with fibers and the measurement of the disturbance or alteration of this field due to these fibers are indirect, feasible and non-destructive method for the quantification of the presence of steel fibers, as well as their possible orientation. Both factors have a decisive influence over the subsequent behavior of the structure (Blanco, 2008 and Pujadas, 2008), thus the possibility of measuring them acquires a vital importance in order to guarantee the quality control of the material (Laranjeira, 2010).

The aim of this paper is to introduce, assess and compare several prototypes based on inductive methods, created in order to determine the amount and orientation of the fibers, analyzing their suitability as a systematic control method for SFRC. The relevance of the presented method stands in providing a non-destructive control system which is not only a tool able to determine the amount of fibers present in concrete, but at the same time also makes it possible to know their orientation. Likewise, the method proves to be highly repeatable and reliable. A series of parameters are dealt with (amount of fibers, orientation, age of concrete and type of fiber) and their influence on the measurements and results of the inductive method are analyzed. The purpose of this study is to contribute to the knowledge of FRC in the structural field and to help to spread its use.

\section{PRECEDENTS TO THE INDUCTIVE METHOD}

\subsection{Introduction}

Due to the electric properties of concrete, many research studies have focused on the development and use of electric methods as a system to characterize concrete, with the 
aim of consolidating new applications and non-destructive tests useful for control and diagnosis (Ozyurt et al., 2006).

In this respect, the Spanish regulation UNE 83512-1:2005 included an inductive test with cylindrical specimens, described very briefly, as shown in Figure1. This regulation can be considered to be the first step toward the control method introduced in this article.

Essentially, the magnetic induction test is an application of Faraday's law of magnetism. For such a test, the specimens must be placed within a container with an established geometry. Two copper or aluminum wire coils are placed around the container, constituting the sensor element of the system. Electric current flows through one of the coils (the primary one), generating a magnetic field and, consequently, a magnetic flux which goes through the center of the coil. If this flux is variable, a current is induced in the other coil (the secondary one). Reciprocity exists between the flux generated by one of the coils and the current induced in the other one, and the relationship between them is called mutual induction coefficient, which is a measurement of the magnetic influence between the two coils. It can be proved that this induction coefficient depends only on the shape and distance between the coils, as well as the (ferromagnetic) nature of the materials close to the coils. Therefore, if the material of the specimens changes the induction coefficient also changes.

Fig. 1. Measurement configuration detailed in regulation UNE 83512-1.

\subsection{Theoretical basis for the inductive method}

\subsubsection{Laws of magnetism}

By combining Ampere's and Faraday's laws of magnetism, the inductance $(L)$ of a solenoid (coil), which are functions of the geometry and the surrounding material, is obtained by means of Equation [1]:

$$
L=\mu^{*} k
$$

where: $\mu$ is the effective magnetic permeability of the environment (in $\mathrm{H} / \mathrm{m}$ ) (where symbol $\mathrm{H}$ of Henry is the SI unit of inductance) depending on the temperature (with $\left(\mu_{0}\right)$ being the vacuum magnetic permeability and $(\mu)$ the permeability in another environment).

$k$ encompasses the dependence on the geometry (in $\mathrm{m}$ ).

If a variable current is injected into the solenoid throughout a circuit, there appears an electromotive force $(\mathrm{emf})$ induced in the circuit. This self-induced emf is in opposition to the variation of the current (energy conservation) and is called counter-electromotive force (counter emf).

In the case of mortar or concrete specimens, if the aggregates are not ferric, the permeability can be considered to be that of the vacuum. Besides, if the surrounding material contains ferromagnetic elements (the fibers, for instance), then the effective permeability of the environment $(\mu)$ will be a function weighted by the geometric distribution of the material (see Equation [2]). Therefore, the inductance can be expressed as in Equation [3].

$$
\begin{aligned}
& \mu=\left[\alpha^{*} \mu_{1}+(1-\alpha)^{*} \mu_{0}\right] \quad \text { for any value of } \alpha \in(0,1) \\
& L=\left[\alpha^{*} \mu_{1}+(1-\alpha) * \mu_{0}\right] k \text { for any value of } \alpha \in(0,1) \quad[3]
\end{aligned}
$$

where $\alpha$ is the volume fraction of the inclusions 
$\mu_{1}$ represents the permeability of the ferromagnetic element (the fibers) with $\mu_{1}>\mu_{0}$.

The analytical determination of the adjustment constant $\alpha$, function of the geometry of the location of the materials with regard to the field lines proves to be non-viable, except in cases of very favorable symmetry. Furthermore, it should be recalculated for each type of fiber, different steel composition, different geometry (hooked-ended or wavy), size and aspect ratio. In any case, the increase in inductance produced by placing a prismatic specimen within the coil makes it possible to determine, by means of a previous calibration, the fiber content of the specimen.

\subsubsection{Effective permeability of mixtures}

An alternative way to see this relationship is through the Maxwell-Garnett equation, which relates the increase of the effective permeability of an environment $(\mu)$ when (initially spherical) inclusions of permeability $\left(\mu_{1}\right)$ different to that of the surrounding environment (in this case, with a permeability equal to that of the vacuum $\mu_{0}$ ) are inserted. The equation supposes, correctly in this case, that the size of the inclusions is much smaller than the wavelength of the measurement. Besides, the inclusions do not interact among themselves, nor much less have contact (that only happens with very small doses of inclusions). Sihvola and Lindell particularize the Maxwell-Garnett equation for the case of needle-shaped inclusions (fibers) with random orientation (Sihvola, Lindell, 1992):

$$
\mu=\mu_{0}+\alpha\left(\mu_{1}-\mu_{0}\right) \frac{\mu_{1}+5 \mu_{0}}{(3-2 \alpha) \mu_{1}+(3+2 \alpha) \mu_{0}}
$$

For the usual cases where the volume ratio of the fibers is much lower than the volume ratio of concrete, equations [2] and [4] are approximately equal. When the orientation is not random, the equation is modified. For instance, inclusions aligned with the direction of the magnetic field, increase the effective permeability and almost do not affect inclusions which are perpendicular to the magnetic field. On average with the three coordinate axes, they coincide with the random orientation. Therefore, as it will be shown in section 4.2 Orientation, if the fibers are arranged in parallel with the direction of the magnetic field, the effective permeability is maximum. In contrast, if the fibers are arranged perpendicular to the direction of the magnetic field, the effective permeability is minimal. An interesting result deducted from equations [2] or [4] is that the change in inductance (or in magnetic permeability) is proportional to the content of inclusions.

\subsection{Corporate experience}

At the same time, a German company devised an equipment based on the previously explained principle, capable of measuring with cubic specimens and, at the same time, giving information about the orientation of the fibers. The company HERTZ Systemtechnik GmbH (http://www.hertznet.de/de/products/measurement/bsm100), based in Delmenhorst (Germany) developed an analog system capable of carrying out said test, applicable to cubic specimens of $150 \times 150 \times 150 \mathrm{~mm}$. The system performs a calibration on the basis of the measurement of a given number of standard specimens with different fiber dosages. The measurement protocol requires the introduction of the specimen according to its three axes, in order to determine the fiber ratio oriented in each direction (a fiber along the magnetic flow modifies the induction coefficient, whereas one crossing it yields practically no modification). As a result, the equipment offers an estimation of the amount of fibers and their distribution in each of the directions measured. This equipment can also be used with fresh concrete thanks to buckets suitably designed to the purpose. However, this equipment has certain disadvantages, which are detailed below.

Due to the geometry of the coil, the magnetic field is not uniform throughout the whole central space, which was empirically checked. As a consequence of these signal 
differences, it can be seen that within the cubic specimen those fibers located in the central area will have a larger effect than those located in the edges. Therefore, if the fibers are uniformly distributed the final measurement will be adequate, but if, on the contrary, there are special distributions or accumulations of fibers (fiber balls) in certain areas of the space, they will have a different effect on the final reading depending on whether they are located in the central area or in the upper and lower areas of the specimen being tested. For instance, since the field has an intensity of $75 \%$ in the edges with regard to that generated in the center of the coil, a concentration of fibers a 75\% lower in the center of the specimen will render the same numerical result than the $100 \%$ in one of the edges.

As a result of these considerations, and with the purpose of improving and correcting the dysfunctions previously described, the design of an alternative to the container and the coil previously introduced is proposed, by using coils with a non-uniform distribution. In this way, in spite of the impossibility of obtaining a completely uniform field, it is possible to reduce the difference between the center and the edges, thus achieving a more balanced effect among all the fibers present in the specimen, regardless of their geometrical position.

\section{INDUCTIVE METHOD PROPOSED}

\subsection{Test equipment and differences with the previous methods and systems}

Having explained the difficulties and limitations of the previous equipment (uniform coils leading to certain differences owing to the edge effect), this section introduces the solutions developed in order to improve the equipment. As proposed in the previous section, a single coil is used for the measurement, acting at the same time as both emitter and receptor (that is, acting as both primary and secondary coil, hence avoiding the weight of a secondary coil). Thus, the mutual induction coefficient becomes the self-induction coefficient, self-inductance or simply inductance. The presence of fibers within it will trigger a variation in its inductance; by measuring with an impedance analyzer (HP4192A or Agilent $\mathrm{U} 1732 \mathrm{~A}$ ), its variation depending on the content and orientation of the fibers can be determined. The measurements are performed at a low frequency of $100 \mathrm{~Hz}$, at which both instruments can measure.

Fig. 2. Test equipment: a) Impedance analyzer HP4192; b) Impedance analyzer Agilent U1732A.

Figure 2a shows the test equipment with the upper-mid-range impedance analyzer HP4192A. This equipment allows the configuration of several parameters (voltage, excitation, frequency, averaging, etc.), which makes it very versatile. Even though it is rather heavy (19 kg), it can be mounted on a frame, and it is very convenient for the laboratory tests. Figure $2 \mathrm{~b}$ shows an alternative to the previous equipment, a low-end impedance analyzer Agilent U1732A. Though less versatile, it is autonomous, light, small and very easy to use, especially suitable for in-situ tests. In practice, this model has shown a precision and efficiency in measuring comparable to those of the HP4192A. Both impedance analyzers are suitable for carrying out the test, but due to its autonomy and size, the Agilent U1732A seems to be the most appropriate one for the quality control in the work site.

During the process of research and improvement of the method, three different coils were developed (see Fig. 3). They are described below:

- Uniform continuous coil: a coil with about 8,800 turns and $12 \mathrm{H}$ (Henry, SI unit of inductance) is devised in order to contrast its working behavior to that of the tested equipment. With this coil, the validity of the method with a single coil is checked. 
The density of turns throughout the inductance is constant, but the field in the edges is $25 \%$ lower compared to that of the center. In other words, four fibers located in the center of the inductance would yield the same reading than five fibers in the periphery.

- Non-uniform continuous coil: in order to create a uniform field inside the coil, it is proposed to use a coil with 2,200 turns and $0.56 \mathrm{H}$, with thicker winding in the edges than in the center and with a pyramidal shape. Thus, despite the impossibility to obtain a completely uniform field, the difference between the center and the edges is reduced, hence obtaining a more balanced weighting among all the fibers present in the specimen, regardless of their geometrical position. Thanks to this configuration, the uniformity of the field within the coil improves: the field in the edges is a $13 \%$ larger with regard to that of the center. That is, eight fibers located in the center of the inductance would yield the same reading than seven fibers in the periphery.

- Discontinuous coil: discontinuous coiling, as shown in figure 3c, allows the magnetic field to be constant throughout the interior of the symmetry axis of the inductance (or coil) with an error lower than 5\%. The biggest difficulty in carrying out the experiment lies in the manual coiling of 2,354 turns which must be performed on the inductance until reaching $1.2 \mathrm{H}$. In any case, the increase of the inductance due to $1 \mathrm{~kg} / \mathrm{m}^{3}$ of fiber is about the resolution of the meter.

Fig. 3. Coils: a) Uniform continuous coil; b) Non-uniform continuous coil; c) Discontinuous coil.

Table 1 summarizes the characteristics of each of the coils previously described.

The entries in Table 1 of an electric nature can be interpreted as merit factors of the coils. Thus, the impedance $Z$ (in module and phase) provides the relationship between tension (voltage) and current in the coil. The (electric) resistance $R$ refers to the copper wire the coils are made of. Finally, the resonant frequency $f_{\text {res }}$ gives the highest frequency at which the sensor can work. Above this resonant frequency the sensor behaves as an equivalent stray capacitance $C$ due to the closeness of the wires in the coiling, losing the capacity to quantify the amount of fibers.

\section{$3.2 \quad$ Test methodology}

Testing consists of measuring the self-induction change experienced by the inductance wrapping the specimen according to the three coordinate axes. In other words, a specimen is placed on a non-metallic surface (with no metallic elements within a distance of $20 \mathrm{~cm}$ either), beginning by placing the concrete-pouring face upwards (axis Z), for instance. The specimen is then wrapped by the inductance, as shown in Figure 2, and the increase of the inductance is measured. Next, the inductance is removed, the specimen is turned over towards axis $\mathrm{Y}$, the measurement is repeated and then it is turned once more, towards axis $\mathrm{X}$, and the measuring is repeated again (see Fig.4).

Fig. 4. Test process according to the three axes.

The average of the three measurements will be, as first approximation, independent from the orientation of the fibers. In other words, information about the dosage of the sample is provided. On the other hand, the dispersion in the measurements of the three axes gives information about the orientation of the fibers. 
Although currently the equipment is only applicable to cubic specimens, the method could be rearranged for its use with cylindrical specimens by modifying the sensor coil, or by studying methods of signal processing. In this respect it must be highlighted that the use of cubic specimens provides valuable information about the orientation of the fibers according to the three main axes of the specimen.

\subsection{Results from contrasting}

By using a prismatic coil, more representative results are obtained, since it weights each of the fibers present in a more even way, regardless of their location. The industrial manufacturing of a coil with such geometry is more complex than that of a conventional coil, but developing one with the same number of turns as a conventional one would yield improvements in the resolution of the measurement.

Figure 5 shows the curves which relate the results obtained after measuring the same elements of SFRC with each of the coils. The uniform continuous coil and the discontinuous coil are compared to the non-uniform continuous coil (Fig. 5a and Fig. 5b, respectively). The results from this figure indicate a strong linear relationship for the different types of coils.

Fig. 5. Relationship between the results from the different coils: a) Uniform and non-uniform continuous coil; b) Non-uniform continuous coil and discontinuous coil.

Apart from errors in measuring and limitations in the resolution of the instruments, the graphs in Figure 5 show the linear and proportional relationship between the increase of inductance and the increase of ferric material. This proportionality does not depend on the coil used for the measurement. This result verifies Equation (3) experimentally, since $\alpha$ is a very small term (the increase in volume of fibers with regard to the volume of the whole specimen and its surroundings); and the term depending on $\mu_{0}$ is calibrated. In any case, this equation has its limitations when "connected" fibers are considered, as will be explained in section 4.3 Type of fiber.

\section{ANALYSIS PARAMETERS}

\subsection{Amount of fibers}

Because of the dependence between the amount of fibers and the measured inductance and its simplicity and economy in its implementation, this method seems to be the most suitable system for the verification of the dosage of the SFRC in quality controls.

Figure 6a shows the results from an experiment where cubic specimens with several known amounts of fibers (with increases of $15 \mathrm{~kg} / \mathrm{m}^{3}$ ) were tested; then control measurements were carried out in order to verify the fiber content in each specimen, obtaining a first reference straight line correlating the increase in inductance and the fiber dosage. Figure $6 \mathrm{~b}$ shows the results obtained for the quality control of specimens from another series with $40 \mathrm{~kg} / \mathrm{m}^{3}$ and $60 \mathrm{~kg} / \mathrm{m}^{3}$. In this case the type of fiber is different from that of Figure 6a, and a straight line with a different slope is obtained (the influence of the type of fiber in the test is explained in section 4.3 Type of fiber).

Fig. 6. Application of the inductive method for the control of the amount of fibers in cubic specimens: a) dosage line I; b) dosage line II. 
Figure $6 \mathrm{a}$ and Figure $6 \mathrm{~b}$ prove the applicability of the method and the results obtained with concrete specimens cast with cubic molds. However, this method can also be used with cubic samples cut from prismatic specimens or larger elements.

In a second experiment, samples obtained from cutting prismatic specimens $(150 \mathrm{x}$ $150 \times 600 \mathrm{~mm}$ ) were used, following Figure7a. According to that figure, the samples are cut at a distance of $75 \mathrm{~mm}$ ( $>\mathrm{L}_{\text {fiber }}$ ) from the edges in order to avoid the possible edge or wall effects generated by the molds. The type of fiber used in this experiment was the same that was used in the experiment presented in Figure $6 \mathrm{~b}$ (length of $50 \mathrm{~mm}$ and diameter of $0.60 \mathrm{~mm}$ ).

Fig. 7 a) Sketch of the cutting of cubic samples $(150 \mathrm{~mm}$ ) obtained from a prismatic specimen; $b$ ) Results from the control of the amount of fibers in cubic samples (dosage line III).

When comparing the results from the same type of fiber (Fig.6b and Fig.7b), it can be observed that the correlation between variation of inductance and dosage (called dosage lines II and III, respectively) hardly varies, which can be due to the fact that the effects of concreting and the edge effect or wall effect (see section 4.2.1) only affect the orientation of fibers, but not the dosage of the mixture of SFRC.

Likewise, the data gathered in Figure 6 and Figure 7 reveal the capacity of the test method for obtaining accurate results with specimen-sized elements as well as with cubic samples obtained from larger elements. Besides, the evident linearity in the correlation between increase of inductance and dosage makes the calibration of the line for the fiber under consideration remarkably easier (Section 4.3 will deal with the influence of the type of fiber on the measurements of inductance). A line is defined by two points: one of them is imposed by the dosage of $0 \mathrm{~kg} / \mathrm{m}^{3}$, since it has no fibers, inductance is not affected. Thus, it is only necessary to know the increase of the inductance generated by a given dosage of the fiber used.

\subsection{Orientation}

\subsubsection{Physics principle of the method}

SFRC is not an isotropic material; the fibers do not provide a uniform reinforcement in the three direction with the same efficiency in all of them (Laranjeira 2010d). In most of the cases preferential orientations in the concrete matrix occur as a result of several aspects, being the wall-effects introduced by the formwork (Romualdi and Mandel, 1964; Kameswara, 1979; Krenchel, 1975; Soroushian and Lee, 1990; Hoy, 1998; Stroeven, 1999; Kooiman, 2000; Van Gysel, 2000; Dupont and Vandewalle, 2005) and the fresh-state properties of SFRC (Grünewald, 2004; Stälhi and van Mier, 2008; Ferrara et al., 2008; Martinie et al., 2009) two of the most significant.

Assuming an infinitely large volume of concrete, fibers would be expected to orient with equal probabilities in different directions in space. Nevertheless, boundaries are always present in concrete elements the probability to orientate randomly near the boundaries is very low (Soroushian and Lee, 1990). In such cases, fibers tend to orientate parallel to the boundaries. This phenomenon is known as the wall effect.

Studies have been carried out to determine to what extent do the fresh-state properties (namely flow properties) of FRC affect fiber distribution and orientation of fibers (Grünewald 2004; Stälhi and van Mier, 2008). The conclusions from the study presented by Stälhi and van Mier confirm that fibers align with the flow of fresh concrete and the alignment has a direct influence on the bending strength (better fiber-alignment leads to a higher bending strength). On the contrary, conventional FRC (non self-compacting concrete 
or non- ultra-fluid) presents large scatter in the results of bending strength, decreasing the characteristic values of strength (Kooiman 2000).

Other factors influencing the orientation of fibers are concrete pouring and the work-site application system, the type of vibration and the production method (Laranjeira 2010a). This phenomenon of preferential orientation can be an advantage or disadvantage depending on the application and, therefore it is of special importance being able to control it.

Due to the physical nature of the magnetic field, the fibers located in a position parallel to the direction of the field (Fig. 8b) will vary the inductance of the coil, whereas those in a perpendicular position (Fig. 8a and Fig. 8c) will show practically no variation. This simple physics principle will make it possible to determine the orientation of the fibers according to the main axes of the specimen.

Fig. 8. Diagram of a fiber aligned to axis $x$ and affected by the magnetic field created by a coil turned around according to its three main axes: a) according to axis $x ; b$ ) according to axis $y ; c$ ) according to axis $z$.

Therefore, since a fiber along the magnetic field modifies the induction coefficient whereas one across it practically does not modify it, the fraction of fibers oriented in each direction can be determined if, using the coil as a sensor, the inductance is measured by wrapping each specimen sequentially, three times, according to the three coordinate axes (see Fig. 8).

\subsubsection{Experimental verification}

In order to corroborate such circumstance, the following experiment was carried out: the fibers are suspended, in only one direction, within a methacrylate cube, with the help of a sponge of the same size as the interior of the cube; the measurements are repeated with the fibers placed parallel and perpendicular to the magnetic field. The results obtained are shown in Figure 9.

Fig. 9. Measurements of fiber orientation for: (a) uniform continuous coil; (b) non-uniform continuous coil.

The results shown in Figure 9 clearly indicate the detection of the orientation of fibers; the difference between the empty coil and the coil with the fibers perpendicular to the field (Fig. 8a and Fig. 8c) is small (11-13\%), whereas the difference becomes remarkable (87$89 \%$ ) in the case of the coil with the parallel fibers (Fig. 8b).

If the contribution of the fibers to the inductance is considered to be the value of the inductance measured with fibers minus the value of the coil in the vacuum, and the $100 \%$ is assigned to the sum of the variations with fibers perpendicular and parallel to the field:

- In the case of the uniform continuous coil, the increase for perpendicular fibers is of $\Delta L_{90}=(12,29 H-12,24 H)=0,05 H$ and for parallel fibers, of $\Delta L_{0}=(12,64 H-12,24$ $H)=0,40 \mathrm{H}$. hence, the growth is of a $11 \%$ for perpendicular fibers $100 * \Delta L_{90} /\left(\Delta L_{90}+\Delta L_{0}\right)$ and of a $89 \%$ for parallel fibers $100 * \Delta L_{0} /\left(\Delta L_{90}+\Delta L_{0}\right)$.

- With the non-uniform continuous coil, on the other hand, it is of a $13 \%$ in the perpendicular situation and of a $87 \%$ in parallel, of the same magnitude level than with the previous coil, showing that in both cases (with both coils) the difference is remarkable. 


\subsubsection{Preferential directions}

The orientation of the fibers in hardened concrete is the result of a chain of stages the FRC goes through from mixing to hardening within the formwork. The boundary conditions specific to each stage of the production process, as well as the actions imposed (wall effect, gravity, external vibration, etc.) induce numerous interaction stages where the orientation of the fibers is modified (Laranjeira et al., 2010b; Laranjeira et al., 2010c). In this regard, the measurement on specimens reveals two directions where fibers are more aligned than in the third one (vertical, axis z), creating thus a preferential plane of orientation (the horizontal one). Figure 10 shows the results from the percentages of fiber orientation according to the three main axes in specimens with different amounts of fibers. The process of calculation of the percentages is the same as indicated above (Section 4.2.2).

Fig. 10. Distribution of fiber orientation (\%) in the three axes for specimens with: a) $20 \mathrm{~kg} / \mathrm{m}^{3}$; b) $30 \mathrm{~kg} / \mathrm{m}^{3}$ and c) $40 \mathrm{~kg} / \mathrm{m}^{3}$.

The values from the graphs in Figure 10 indicate the existence of a preferential horizontal plane in the orientation of fibers for the three dosages used. This phenomenon is the result of the fiber casting or placing method; it is not caused by the amount of fibers, as the distributions in Figure 10 show.

The compaction process of SFRC becomes a significant influence on the orientation of the fibers. During that process the fibers tend to orientate parallel to the formwork surface (wall effect). It must be mentioned that this effect is only local (in the concrete in contact with the formwork), but can be significant in thin elements and when the fibers are long (see Fig. 11). Moreover, vibration can also trigger the rotation and alignment of the fibers preferentially in a specific direction (Gettu et al., 2005). Specifically, external vibration tends to orientate fibers in a plane perpendicular to the direction of the vibration (Eddington and Hannant, 1972), with a tendency towards a plain orientation of the fibers (Soroushian and Lee, 1990; Kooiman, 2000): the more the FRC is subject to vibration, the more the fibers tend to align themselves in the horizontal plane.

Fig. 11. Preferential orientation (wall effect) in a thin element.

Several researchers have highlighted the remarkable influence of casting of the elements (Toujanji and Bayasi, 1998; Markovic, 2006; Torrijos et al., 2008) and the direction of the concreting on the orientation of the fibers (Torrijos et al., 2008; Stälhi et al., 2008; Dozio, 2008). This phenomenon is observed when measuring the orientation of the fibers in concrete specimens from cubic molds and in cubic samples cut from prismatic elements with dimensions of 150x150x600 mm (following the cutting pattern indicated in Fig. 7a). Figure 12 (corresponding to two different amounts of fibers: 40 and $60 \mathrm{~kg} / \mathrm{m}^{3}$ ) and Table 2 show the results of the distribution of fiber orientation (in percentage) obtained from said experiment. (Where $\mathrm{Hx}, \mathrm{Hy}$ and $\mathrm{Vz}$ stands for horizontal $\mathrm{x}$, horizontal $\mathrm{y}$ and vertical $\mathrm{z}$ axis respectively).

Fig. 12. Distribution of the orientation of the fibers in cubic specimens and samples (with 40 and $\left.60 \mathrm{~kg} / \mathrm{m}^{3}\right)$.

Table 2. Percentages of fibers (\%) for different directions and with two different amounts of fibers.

The results presented in Figure 12 and Table 2 show an alignment of the fibers in the horizontal plane (axes Hx and Hy) for both dosages; however, it seems more interesting to compare the results obtained from the cubic specimens to those obtained with the samples cut from prismatic specimens. In the latter, the horizontal plane remains as the preferential orientation plane, but the alignment of the fibers with the axis Hy augments significantly. This phenomenon is due to the fact that the influence of the flow is intrinsically 
related to the pouring and placing system and with the geometry of the element cast with concrete (in this case, a prismatic mold). These results coincide with the studies carried out which point out that the pouring or flow of concrete cause a preferential orientation of the fibers (Grünewald, 2004; Stälhi et al., 2008; Lapa, 2007). Their alignment with the flow also increases at increasing flow distance.

The possibility of knowing the orientation of the fibers in an element turns out to be relevant information with regard to the mechanical behavior of the element, since the orientation has direct consequences over the post-cracking strength of the material. When cubic specimens or samples are tested following the configuration of a double-punch test (like the Barcelona UNE 83515:2010 test (Molins et al., 2009), but without a control chain for circumferential strain), the residual strength was influenced by the orientation of the fibers, depending on whether they are aligned in a direction favorable to the strength of the stresses generated. Another example can be found in the flexural strength tests with prismatic specimens of FRC (UNE EN 14651:2007+A1:2008 or NBN B 15238), where the specimen is turned around andthe horizontal plane of preferential orientation of the fibers does not correspond with the plane of application of the load (see Fig. 13). This rotation of the specimen will yield results of residual strengths lower than those obtained if the plane of preferential orientation of the fibers coincided with the plane of load application.

Fig. 13. Specimen for flexural strength test: a) concrete pouring position; b) test position.

\subsection{Type of fiber}

The type of fiber used for the production of SFRC is a factor that must be taken into account when applying the inductive method, since the geometry of fibers (with regard to length, diameter or contact among them inside the concrete matrix) causes a different result of the measurement of self-induction in the inductance. Therefore, the correlation between the fiber content and the inductance increase for each typology of fiber must be calibrated in order to determine the dosage in a systematic way (as was pointed out in Section 4.1 Amount of fibers).

\subsection{Age of concrete}

As it has been previously described, the components of concrete (aggregates, water and cement) are not ferromagnetic, and this characteristic is independent from the state of concrete (be it in fresh state or in hardened state). This invariability of the ferromagnetic properties of concrete guarantees that the results obtained when performing the test 24 hours after concrete-pouring will be the same as those obtained after 28 days. With the aim of verifying this hypothesis, the following experiment was carried out: 12 cubic specimens of SFRC were cast, and measurements were taken with the inductive method at different ages. Figure 14 shows the graph with the results (in $\mathrm{H}$ ) obtained at both ages when measuring with the uniform continuous coil according to the three coordinate axes (the $\mathrm{X}$ axis corresponds to the concrete-pouring face).

Fig.14. Results obtained (inductance) with each of the coordinate axes at the SFRC ages of 7 days and 90 days.

The values from Figure 14 are an indication of the repetitiveness in the values from the measurements at both ages (7/90 days). This experiment confirms that, since the nonferromagnetic properties of the components of concrete remain constant through time, the inductive method can be suitably used at any moment and is independent from the age of concrete.

Table 3 shows the inductance increase results obtained like the measurements from Figure 14 (in this case the test equipment consisted of: HP4192A analyzer and uniform 
continuous coil). The values show how the difference in sample age between the two measurements is non-existent or negligible in most of the cases.

Table 3. Measurements from each specimen by means of HP4192A analyzer uniform continuous coil taken at 7 days and 90 days.

In previous experiments, introduced in Section 4.2.3 Preferential directions, a preferential orientation of fibers was detected in the plane of the concrete-pouring face of the cubic specimen, and lower induction values were measured in axis $\mathrm{Z}$ direction. This phenomenon, as has been previously explained, is caused by several factors, such as the compaction of concrete. An excessive vibration of the specimen aligns fibers in the plane of the concrete-pouring face. However, the results presented in Table 3 and Figure 14 do not show a clear orientation in that plane; on the contrary, the values from the three axes are similar. Probably, vibration of the specimens was not carried out, but instead external knocking of the molds was performed.

\section{APPLICATION OF THE INDUCTIVE METHOD WHEN THE AMOUNT OF FIBERS IS UNKNOWN}

With the aim of determining the accuracy of the inductive method for assessing the content of fibers in concrete, a blind test (the dosage of fibers was not known beforehand) was carried out with 12 cubic specimens of SFRC with the same type of fiber and 6 different amounts of fibers (at intervals of $5 \mathrm{~kg} / \mathrm{m}^{3}$ ). The test was performed in order to determine the fiber content of each of the specimens.

The inductance was measured by means of a cheap hand impedance measurer (LCR) by Agilent, model U1732A, at $100 \mathrm{~Hz}$ (some inductance measurements were repeated at 120 $\mathrm{Hz}$ with differences lower than the resolution of the instrument). This economic instrument can only measure at certain frequencies. In this case, a low frequency equal to $100 \mathrm{~Hz}$ was selected. The inductance of the discontinuous coil, $1.2 \mathrm{H}$ as mentioned in Section 3.1, is the minimum inductance value that made it possible to observe the inductance changes due to a variation of $1 \mathrm{~kg} / \mathrm{m}^{3}$ of fiber in the specimen and it is above the resolution of the instrument. In other words, the empirical determination of $k$ comes from measuring the coil in the vacuum. Thus, $\mathrm{k}=1.2 \mathrm{H} / \mu_{0}$.

By means of the system previously described, the inductance changes induced by each of the twelve samples are measured. It must be highlighted that each set of measurements of the three orientations for each of the twelve specimens can be performed by one single operator in less than an hour. After the necessary time for the stabilization of the measurement, the fluctuations were lower than $0.3 \mathrm{mH}$.

Before proceeding with the analysis of the results, it is necessary to explain the difference between the theoretical dosage and the real dosage of the specimen. The theoretical dosage is the dosage used in the mixture (weighted and introduced into the paste in the exact amount). However, when the concrete is poured into the mold, it may occur that the proportion of the mixture drifts from the theoretical amount. That dosage is called the measured real dosage; however, the variation is so small that it can be assumed to be the theoretical dosage.

In order to determine the real dosage and to calibrate the method (in other words, the increment of inductance corresponding with the exact amount of fibers) it is necessary to count the fibers. This procedure is carried out by crushing all the specimens, collecting the fibers and weighting them according to [EN 14721:2008]. The average number of fibers in specimens $35 \mathrm{~A}$ and $35 \mathrm{~B}$ were used as the standard for the assessment of the amount of fibers. The comparison between the exact dosage of the other samples measured by [EN 
14721:2008] and the dosage inferred by the magnetic method over the pattern, has allowed to measure the goodness of the magnetic method.

Table 4 provides the predicted dosages after the measurement, at 90 days, of the variation of inductance in the specimens previously introduced, with the three coils (nonuniform continuous, uniform continuous and discontinuous coils). Additionally, Table 4 shows the results of the abovementioned comparison between real dosage and dosage measured by the magnetic method.

Table 4. Results with HP4192A analyzer from the experiment with cubic specimens of SFRC compared with measured real dosage [EN 14721:2008].

In view of the results reproduced in Table 4, the error of the inductive method is less than $2 \mathrm{~kg} / \mathrm{m}^{3}$ in all cases. Moreover, because the magnetic field is more uniform in the discontinuous coil than in the other two coils, the dispersion of the measurements between the three coils may be indicative of heterogeneity in the distribution of fibers within the specimens. It can also be observed that the test equipment is accurate enough to distinguish the real dosage in the specimens and being able to assign a theoretical dosage to each specimen with no risk of error.

\section{CONCLUSIONS}

The growing use of SFRC structures highlights the necessity for new non-destructive methods for quality control, combining practicality and economy with efficiency. With that purpose in mind, a control method was developed on the basis of the UNE 83512-1 regulation. This method makes it possible to control the dosage and orientation of the fibers in SFRC elements.

In order to prove the capacity of the aforementioned test method a detailed analysis was carried out, and the following can be concluded:

- The developed test equipment is able to detect the dosage of a SFRC element with a verified accuracy better than $5 \mathrm{~kg} / \mathrm{m}^{3}$.

- The developed method makes it possible to determine the percentage of fibers aligned according to the main axes, information which can be advantageously applied for the design and improvement of the structural response of the element.

- The age of concrete does not influence over the test results. Then, the test can be carried out at any age of the SFRC.

- It is possible to obtain a dosage line (from which the amounts of fibers depending on the inductance measurements are obtained) for each type of fiber with only one reference measure.

Application of this method is limited to the sensor samples and the field uniformity inside. Other systems apply to structures, although its application is limited to laboratory results. A magnetic system with a lesser dependency on the geometry of the sensor could, in future, analyze structural elements in situ.

All the properties of the test method described lead to the conclusion that the measurement of the change of inductance generated by the presence of steel fibers in the concrete is a reliable, simple, fast and economic method for the detection of the amount of fibers as well as their orientation. The inductive method has the potential to become a key tool for the quality control and diagnosis of SFRC elements, being of special interest in the field of prefabrication. 


\section{ACKNOWLEDGEMENTS}

The authors wish to thank the companies FCC, S.A. (HATCONS Project), PROMSA, ESCOFET and CEMEX for their partial financing and their participation in the experimental campaigns carried out. The authors also wish to thank the Ministry of Science and Innovation (MCINN) on the grounds of the CONSFIB project (reference: BIA 1010-17478). The second and the third authors wish to express their acknowledgement to the Comissionat per a Universitats del DIUE de la Generalitat de Catalunya i del Fons Social Europeu for the FI grant and to the Polytechnic University of Catalonia for the FPI-UPC grant, respectively. The same authors are also grateful for the support provided by the Col-legi d'Enginyers de Camins, Canals i Ports de Catalunya.

\section{REFERENCES}

Aguado, A., Laranjeira, F., (2007) Presentación del anejo de hormigón con fibras de la EHE y ecuación constitutiva del hormigón con fibras. Cátedra BMB-UPC: Aplicaciones estructurales de hormigón con fibras. Barcelona, 2007.

Barragán, B.E. (2002) Failure and toughness of steel fiber reinforced concrete under tension and shear, PhD Thesis, Universitat Politècnica de Catalunya.

Blanco, A., Pujadas, P., de la Fuente, A., Aguado, A. (2010) Análisis comparativo de los modelos constitutivos del hormigón reforzado con fibras, Hormigón y Acero, 61(256): 83101.

Blanco, A. (2008) Durabilidad del hormigón con fibras de acero, Minor thesis, Universitat Politècnica de Catalunya.

Dozio, D. (2008) SFRC structures: Identification of the uniaxial tension characteristic constitutive law, PhD Thesis, Politecnico di Milano.

Dupont, D., Vandewalle, L. (2005) Distribution of steel fibres in rectangular sections, Cement and Concrete Composites, 27: 391-398.

Edington J., Hannant, D.J. (1972) Steel Fibre reinforced concrete. The effect on fibre orientation of compaction by vibration, Materials and Structures, 5(25):41-44.

Faifer, M.; Ottoboni, R.; Toscani, S.; Ferrara, L. (2010) Steel fiber reinforced concrete characterization based on a magnetic probe, Instrumentation and Measurement Technology Conference (I2MTC), IEEE: 157-162.

Ferrara, L., Park, Y., Shah, S.P. (2008) Correlation among fresh State Behavior, Fiber Dispersion and Toughness Properties of SFRCs, Journal of Materials in Civil Engineering, 20(7): 493-501.

Gettu, R., Gardner, D.R., Saldívar, H., Barragán, B.E. (2005) Study of the distribution and orientation of fibers in SFRC specimens, Materials and Structures, 38(1): 31-37.

Grünewald, S. (2004) Performance-based design of self-compacting fibre reinforced concrete, PhD Thesis, Delft University of Technology.

Hoy, C.W. (1998) Mixing and mix proportioning of fibre reinforced concrete, PhD Thesis, University ofPaisley.

Kameswara RAO, C.V.S. (1979) Effectiveness of random fibres in composites, Cement and Concrete Research, 9:685-693. 
Kooiman, A.G. (2000) Modelling Steel Fibre Reinforced Concrete for Structural Design, PhD Thesis, Delft University of Technology.

Krenchel, H. (1975) Fibre spacing and specific fibre surface, In: Neville A, editor. Fibre reinforced cement and concrete, UK: The Construction Press: 69-79.

Lambrechts, A. (2008)Performance classes for steel fibre reinforced concrete: Be critical. BEFIB 2008: 7th RILEM International Symposium on Fibre Reinforced Concrete. RILEM Publications SARL: $1007-1020$.

Lappa, L. (2007) High Strength Fibre Reinforced Concrete: Static and fatigue behavior in bending, PhD Thesis, Delft University of Technology.

Laranjeira, F. (2010) Design-oriented constitutive model for steel fiber reinforced concrete, PhD Thesis, Universitat Politècnica de Catalunya.

Laranjeira, F., Aguado, A., Molins, C. (2010a) Predicting the pullout response of inclined straight steel fibers Materials and Structures, 43(6): 875-895.

Laranjeira, F., Molins, C., Aguado A. (2010b) Predicting the pullout response of inclined hooked steel fibers, Cement and Concrete Research, V. 40: 1471-1487.

Laranjeira, F., Grünewald, S., Walraven, J., Blom, C., Molins, C., Aguado, A.(2010c) Characterization of the orientation profile of steel fiber reinforced concrete, Accepted on Materials and Structures and soon available online.

Lataste, J.F., Behloul, M., Breysse, D. (2008) Characterisation of fibres distribution in a steel fibre reinforced concrete with electrical resistivity measurements, NDT\&E International, 41: 638-647.

Markovic I (2006) High-Performance Hybrid-Fibre Concrete: Development and Utilisation, PhD Thesis, Delft University of Technology.

Martinie L., Rossi, P., Roussel, N. (2010) Rheology of fiber reinforced cementitious materials: classification and prediction, 40(2):226-234.

Molins, C., Martinez J., Arnáiz, N. (2008) Distribución de fibras de acero en probetas prismáticas de hormigón, CD-ROM from the 4th International Structural Concrete Congress (ACHE), Valencia, Spain.

Molins, C., Aguado, A., Saludes, S. (2009) Double Punch Test to control the tensile properties of FRC (Barcelona test). Rev. Materials and Structures (RILEM). Vol. 42, no 4. May 2009: 415425.

NBN B 15-238, 1992 "Essais des bétons renforcés de fibres-Essai de flexion sur éprouvettes prismatiques".

Nuclear Energy Agency, Committee on The Safety of Nuclear Installations (1998) Development priorities for Non-Destructive Examination of Concrete Structures in Nuclear Plant. Nea/Csni/R(98)6.

Ozyurt, N., Mason, T.O., Shah, S.P. (2006) Non-destructive monitoring of fiber orientation using AC-IS: An industrial-scale application, Cement and Concrete Research, 36: 1653-1660.

Pujadas, P. (2008) Durabilidad del hormigón con fibras de polipropileno, Minor Thesis, Universitat Politècnica de Catalunya.

Pujadas, P., Blanco, A., de la Fuente, A., Aguado, A. (2011) Cracking behaviour of FRC slabs with traditional reinforcement. Materials and Structures, Accepted 21 September 2011 (DOI: 10.1617/s11527-011-9791-0). 
Robins, P.J., Austin, S.A., Jones, P.A. (2003) Spatial distribution of steel fibres in sprayed and cast concrete, Magazine of Concrete Research, 55(3): 225-235.

Romualdi, J.P., Mandel, J.A. (1964) Tensile strength of concrete affected by uniformly distributed and closely spaced short lengths of wire reinforcement, ACI Journal, 61(6):27-37.

Roqueta, G., Romeu, J., Jofre, L. (2009) Electromagnetic modeling and characterization of steel fiber reinforced concrete during the pouring process. Antennas and Propagation Society International Symposium, 2009. APSURSI '09. IEEE: 1 -4.

Serna, P., Arango, S., Ribeiro, T., Núñez, A.M., Garcia-Taengua, E. (2009) Structural cast-inplace FRC: technology, control criteria and recent applications in Spain, Materials and Structures, 42 (9): 1233-1246.

Sihvola, A.H., Lindell, I.V. (1992) Effective Permeability of Mixtures. Progress In Electromagnetics Research, PIER 06: 153-180.

http://www.jpier.org/PIER/pier.php?volume=06. Accessed 23 May 2011.

Soroushian, P., Lee C (1990) Distribution and orientation of fibers in steel fiber reinforced concrete, ACI Materials Journal, 87(5): 433-439.

Stälhi, P. (2008) Ultra-Fluid, Oriented Hybrid-Fibre-Concrete, PhD Thesis, Institute for Building Materials ETH Zürich.

Stälhi, P, Custer, R., van Mier, J.G.M. (2008) On flow properties, fibre distribution, fibre orientation and flexural behaviour of FRC, Materials and Structures, 41: 189-196.

Stroeven, P. (1999) Steel fibre reinforcement at boundaries in concrete elements,Proceedings of the 3rd International Workshop on High Performance Fiber Reinforced Cement Composites (HPFRCC3), Mainz, Germany, 413-421.

Torrents, J.M., Juan-García, P., Patau, O., Aguado, A. (2009) Surveillance of steel fibre reinforced concrete slabs measured with an open-ended coaxial probe, Proceedings of the XIX IMEKO World Congress: Fundamental and Applied Metrology, Lisbon, Portugal: 22822284. http://www.imeko2009.it.pt/Papers/FP 633.pdf. 201. Accessed 23 May 2011.

Torrijos, M.C., Tobes, J.M., Barragán, B.E., Zerbino, R.L. (2008) Orientation and Distribution of Steel Fibres in Self-Compacting Concrete, Proceedings of the 7th RILEM Symposium on Fibre Reinforced Concrete: Design and Applications (BEFIB 2008), Chennai, India: 729-738.

Toujanji, H., Bayasi, Z. (1998) Effects of manufacturing techniques on the flexural behavior of steel fiber-reinforced concrete, Cement and Concrete Research, 28(1): 115-124.

UNE 83512-1, 2005 "Hormigones con fibras. Determinación del contenido de fibras de acero". AENOR, Madrid.

Van Damme, S., Franchois, A., De Zutter, D. and Taerwe, L. (2004) Nondestructive Determination of the Steel Fiber Content in Concrete Slabs UIT an Open-Ended Coaxial Probe. IEEE Transactions on Geoscience and Remote Sensing, 42, 11: 2511-2521.

Vandewalle, L., Heirman, G., van Rickstal, F. (2008) Fibre orientation in self-compacting fibre reinforced concrete, Proceedings of the 7th RILEM Symposium on Fibre Reinforced Concrete: Design and Applications (BEFIB 2008), Chennai, India: 719-728.

Van Gysel, A. (2000) Studie van het uittrekgedrag van staalvezels ingebed in een cementgebonden matrix met toepassing op staalvezelbeton onderworpen aan buiging, $\mathrm{PhD}$ Thesis, Gent University. 
UNE EN 14651, 2005 "Test method for metallic fibrered concrete - Measuring the flexural tensile strength (limit of proportionality (LOP), residual)". 
Fig. 1. Measurement configuration detailed in regulation UNE 83512-1.

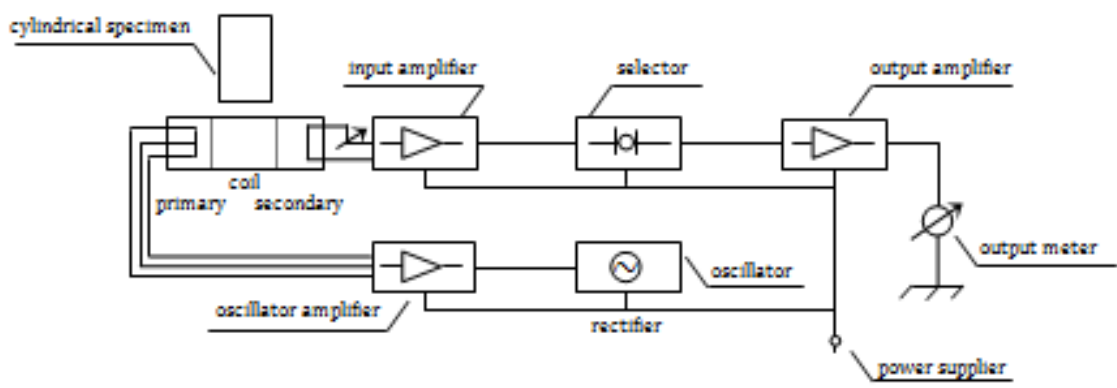


Fig. 2. Test equipment: a) Impedance analyzer HP4192; b) Impedance analyzer Agilent U1732A.

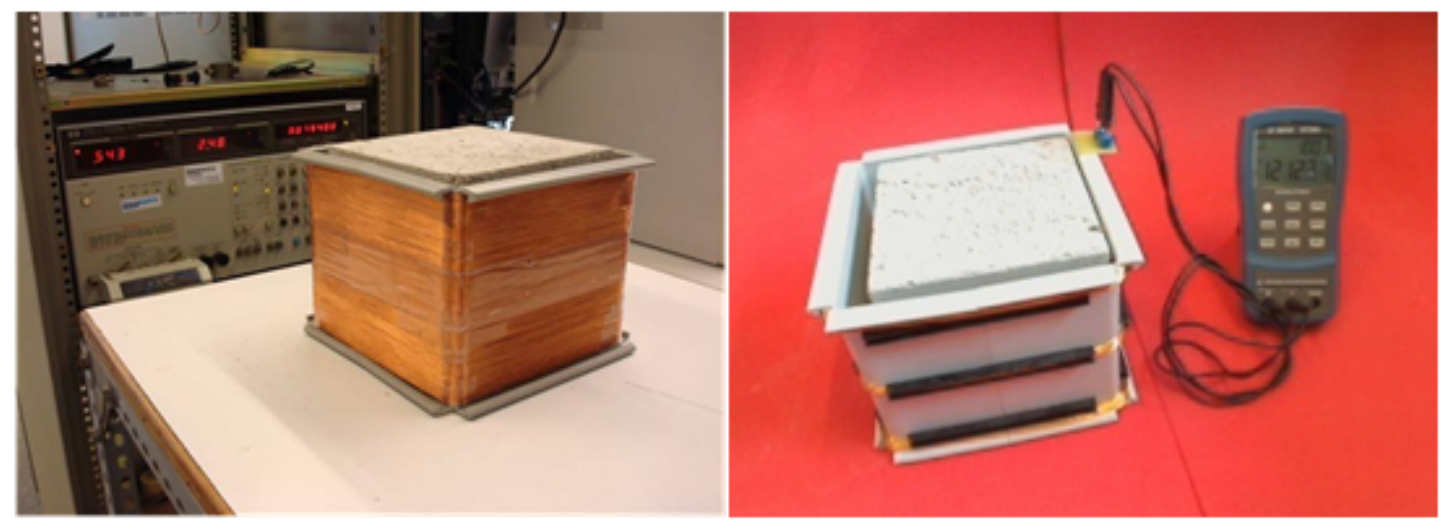


Fig. 3. Coils: a) Uniform continuous coil; b) Non-uniform continuous coil; c) Discontinuous coil.
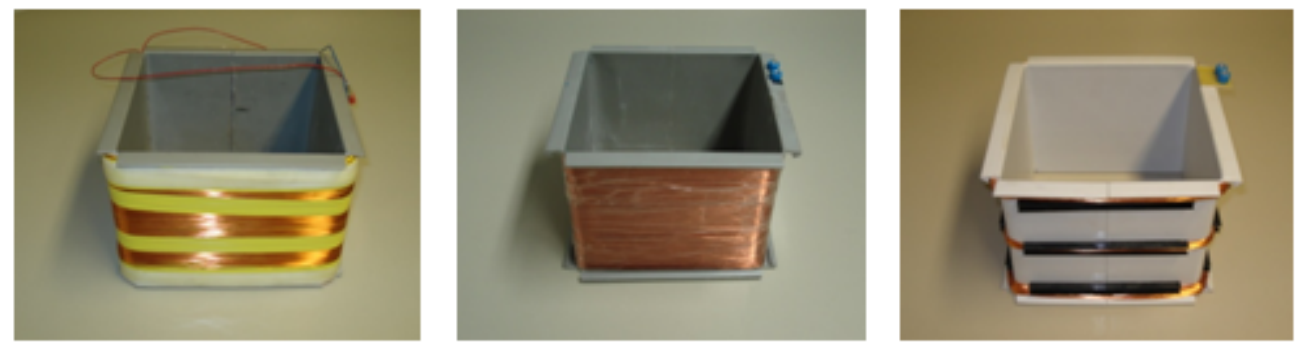
Fig. 4. Test process according to the three axes.
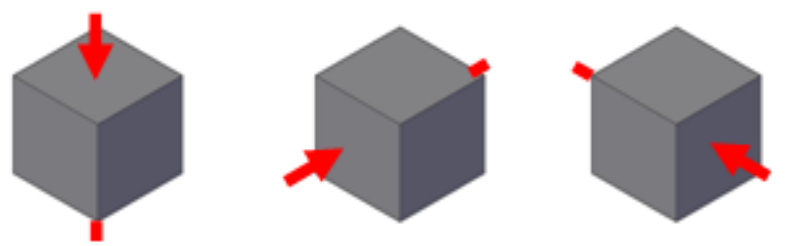
Fig. 5. Relationship between the results from the different coils: a) Uniform and non-uniform continuous coil; b) Non-uniform continuous coil and discontinuous coil.
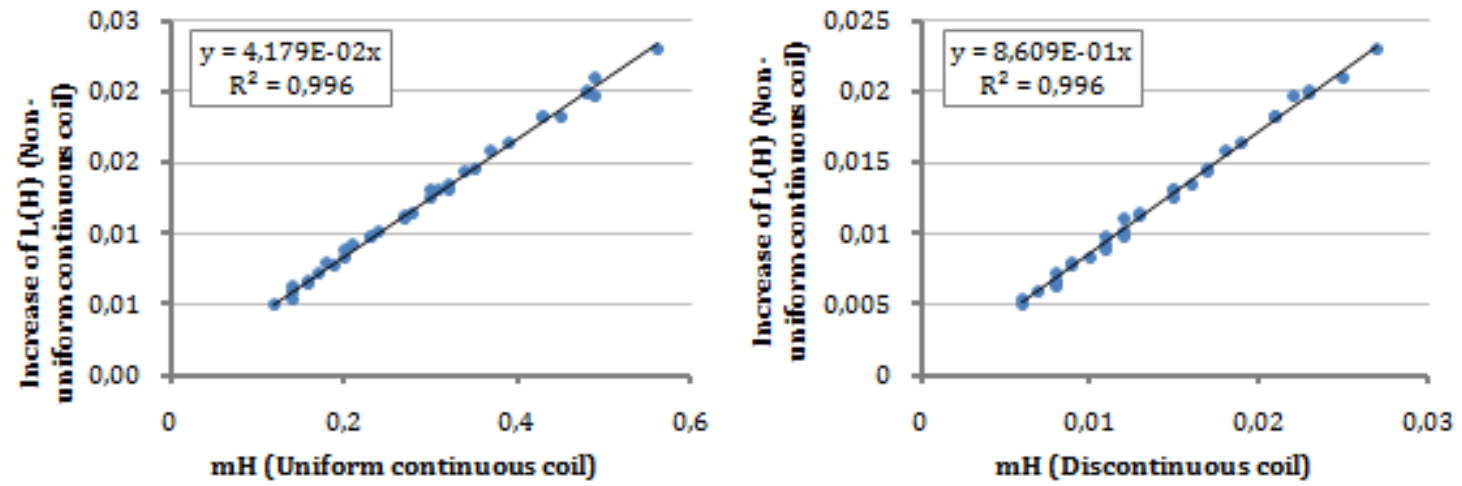
Fig. 6. Application of the inductive method for the control of the amount of fibers in cubic specimens: a) dosage line I; b) dosage line II.
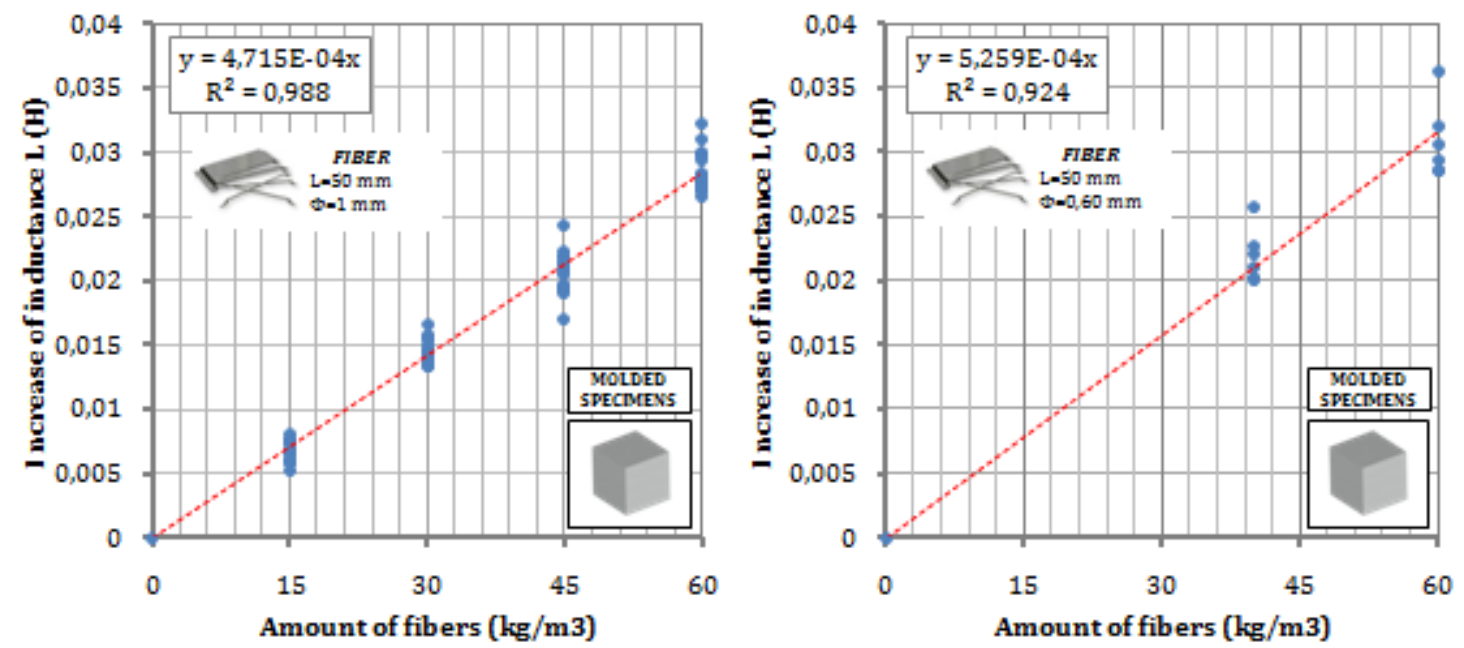
Fig. 7 a) Sketch of the cutting of cubic samples $(15 \mathrm{~cm})$ obtained from a prismatic specimen; b) Results from the control of the amount of fibers in cubic samples (dosage line III).
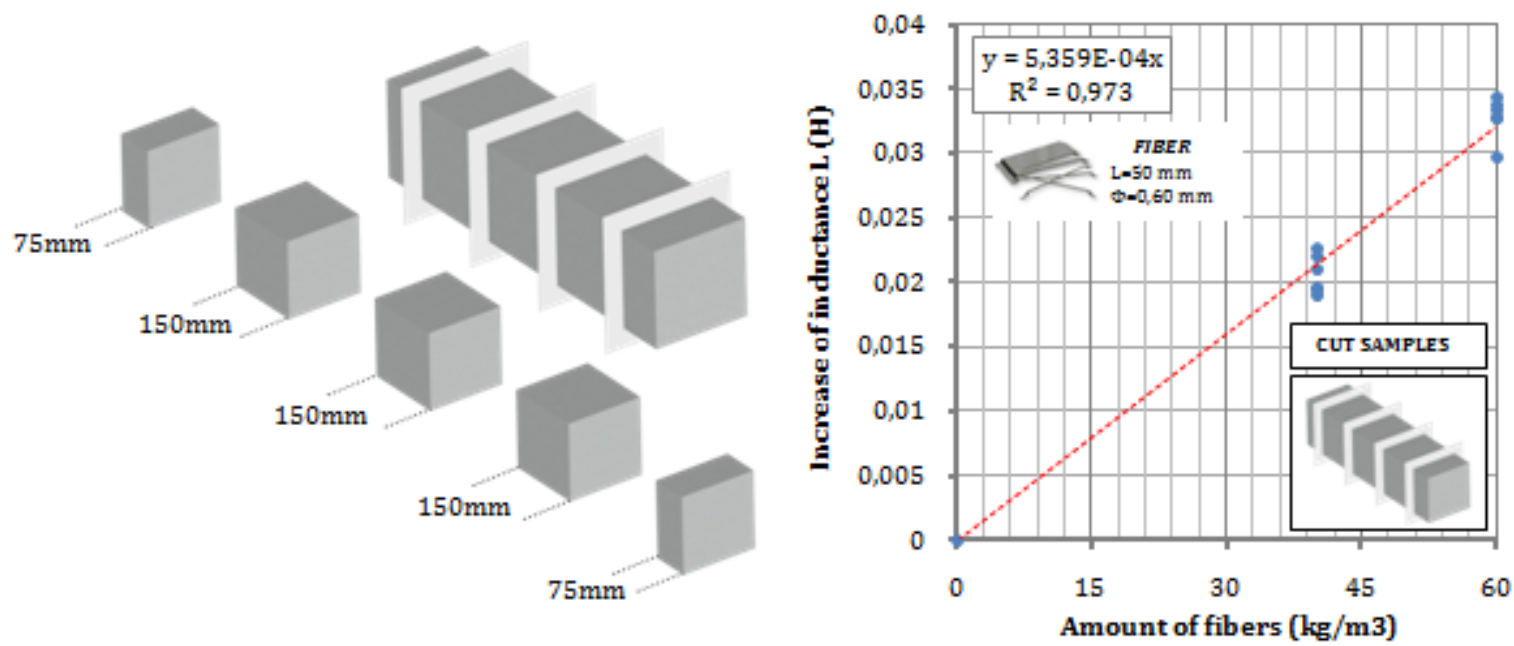
Fig. 8. Diagram of a fiber aligned to axis $x$ and affected by the magnetic field created by a coil turned around according to its three main axes: a) according to axis $x$; b) according to axis and; c) according to axis $z$.
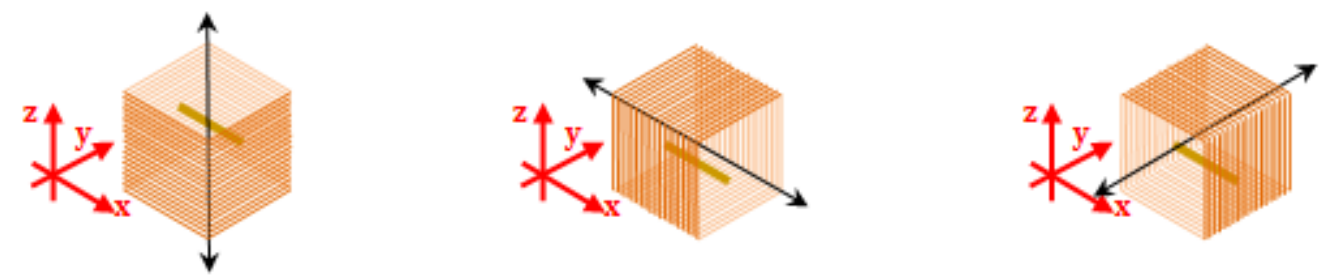
Fig. 9. Measurements of fiber orientation for: (a) uniform continuous coil; (b) non-uniform continuous coil.

a)

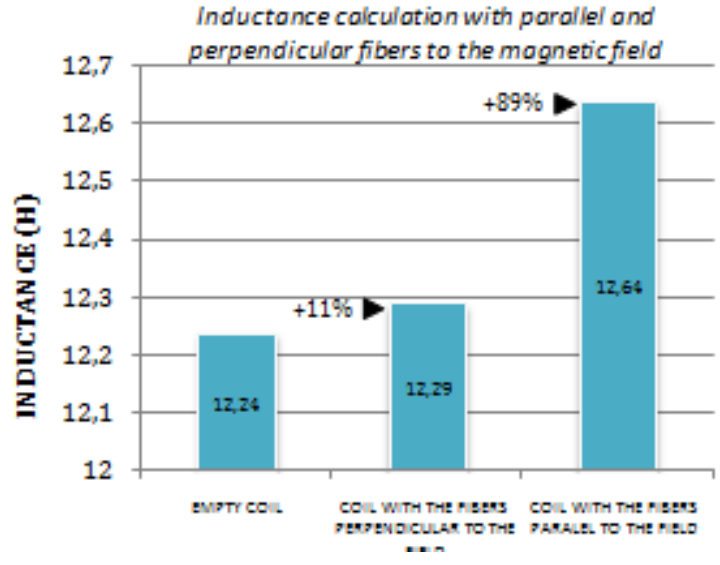

b)

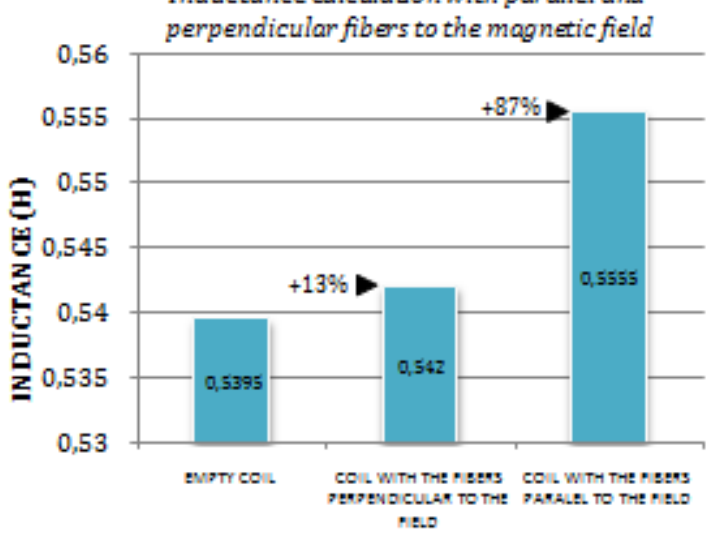


Fig. 10. Distribution of fiber orientation (\%) in the three axes for specimens with: a) $20 \mathrm{~kg} / \mathrm{m}^{3}$; b) 30 $\mathrm{kg} / \mathrm{m}^{3}$ and c) $40 \mathrm{~kg} / \mathrm{m}^{3}$.

Fiber orientation in $20 \mathrm{~kg} / \mathrm{m}^{3}$ specimens

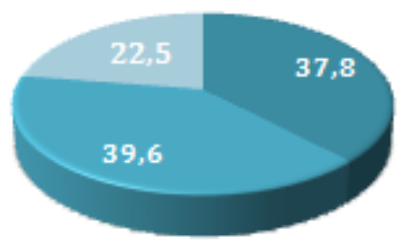

Fiber orientation in $30 \mathrm{~kg} / \mathrm{m}^{3}$ specimens

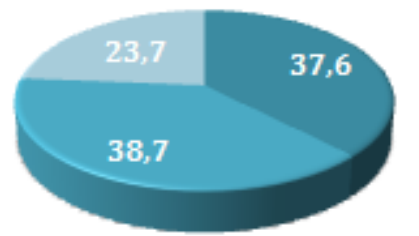

Fiber orientación in $40 \mathrm{~kg} / \mathrm{m}^{3}$ specimens

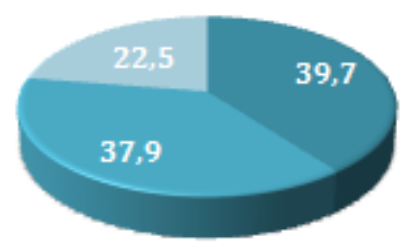


Fig. 11. Preferential orientation (wall effect) in a thin element

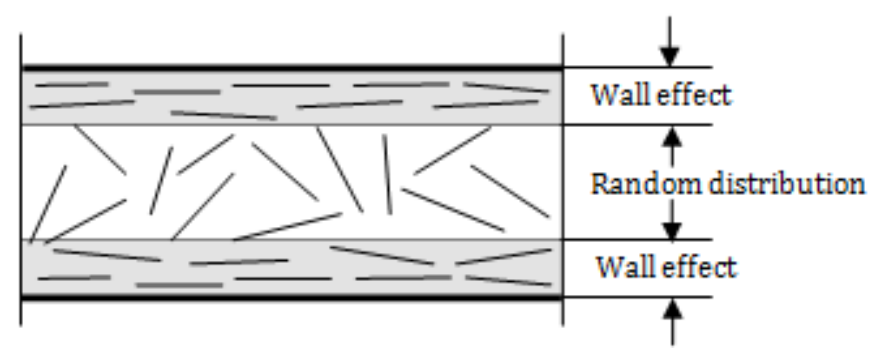


Fig. 12. Distribution of the orientation of the fibers in cubic specimens and samples (with 40 and 60 $\mathrm{kg} / \mathrm{m}^{3}$ ).

Distribution of the orientation of the fibers in cubic specimens and samples with $40 \mathrm{~kg} / \mathrm{m}^{3}$

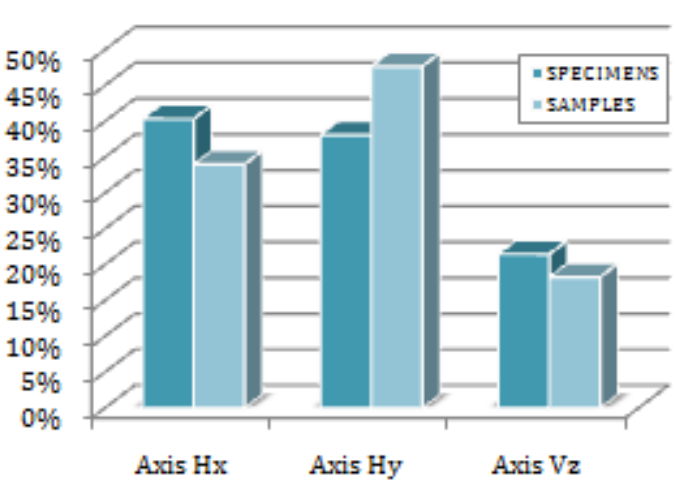

Distribution of the orientation of the fibers in cubic specimens and samples with $60 \mathrm{~kg} / \mathrm{m}^{3}$

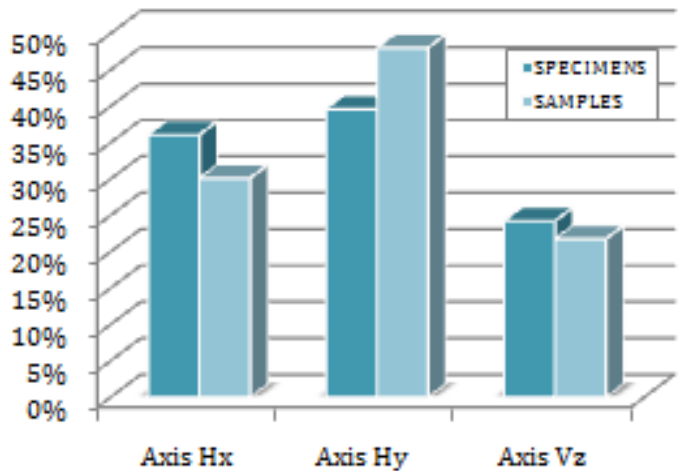


Fig. 13. Specimen for flexural strength test: a) concrete pouring position; b) test position.
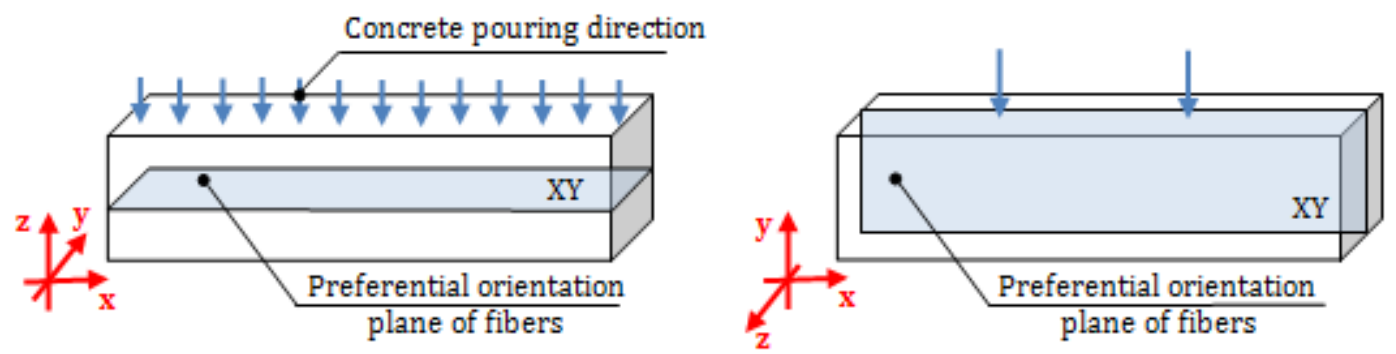
Fig. 14. Influence of the type of fiber on the measurement of the inductance: a) alignment of the fiber; $b$ ) exposure of the fiber to the magnetic field.
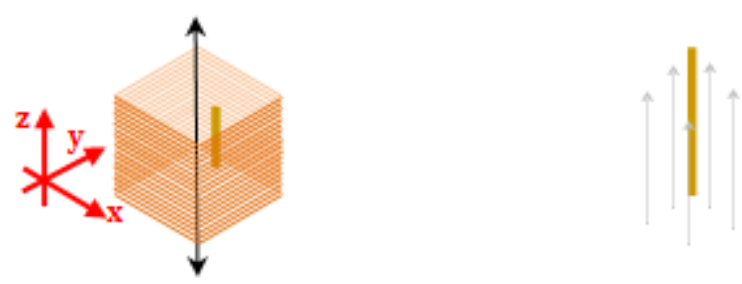
Fig.15. Results obtained (inductance) with each of the coordinate axes at the SFRC ages of 7 days and 90 days.

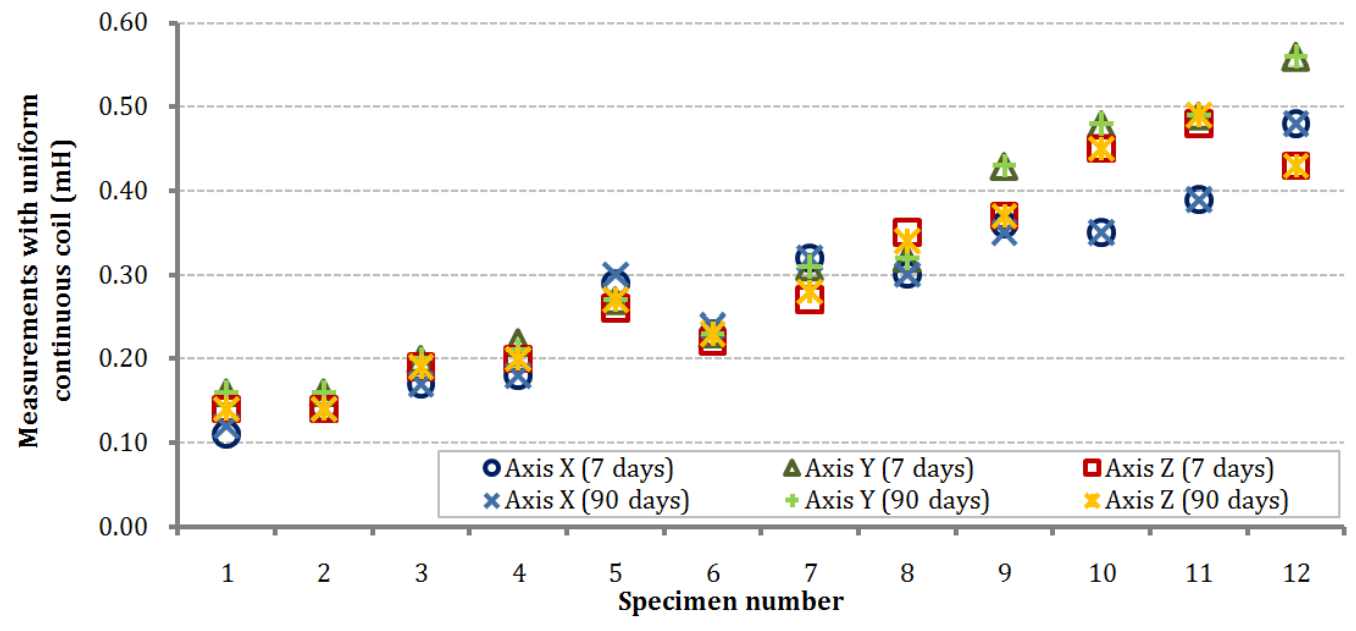


Table 1. Main characteristics of the three coils developed.

\begin{tabular}{lccc}
\hline \multicolumn{1}{c}{ Characteristics } & $\begin{array}{c}\text { Uniform } \\
\text { continuous coil }\end{array}$ & $\begin{array}{c}\text { Non-uniform } \\
\text { continuous coil }\end{array}$ & Discontinuous coil \\
\hline Geometry & $15 \times 17 \times 17 \mathrm{~cm}$ & $15 \times 17 \times 17 \mathrm{~cm}$ & $15 \times 17 \times 17 \mathrm{~cm}$ \\
Turn shape & Square $\left(289 \mathrm{~cm}^{2}\right)$ & Square $\left(289 \mathrm{~cm}^{2}\right)$ & Square $\left(289 \mathrm{~cm}^{2}\right)$ \\
Number of turns & 8,800 & 2,200 & 2,354 \\
Wire length & $5,632 \mathrm{~m}$ & $1,408 \mathrm{~m}$ & $1,600 \mathrm{~m}$ \\
Diameter cable & $0.3 \mathrm{~mm}$ & $0.2 \mathrm{~mm}$ & $0.2 \mathrm{~mm}$ \\
Turns & Positive & Positive & Positive \\
Magnetic field & Non-uniform & Non-uniform & Uniform \\
Theoretical inductance (L) & $12 \mathrm{H}$ & $0.56 \mathrm{H}$ & $1.2 \mathrm{H}$ \\
Module (Z) & $8,106 \Omega$ & $760 \Omega$ & $1,189 \Omega$ \\
Phase (Z) & $79.1 \mathrm{DG}$ & $27.6 \mathrm{DG}$ & $39.9 \mathrm{DG}$ \\
Resistance (R) & $1,540 \Omega$ & $673 \Omega$ & $920 \Omega$ \\
Resonant frequency $\left(f_{\text {res }}\right)$ & $2 \mathrm{kHz}$ & $5 \mathrm{kHz}$ & $20 \mathrm{kHz}$ \\
Equivalent stray capacitance $(\mathrm{C})$ & $0.50 \mathrm{nF}$ & $2.00 \mathrm{nF}$ & $0.05 \mathrm{nF}$ \\
Weight & $4.70 \mathrm{~kg}$ & $0.95 \mathrm{~kg}$ & $1.15 \mathrm{~kg}$ \\
\hline
\end{tabular}


Table 2. Percentages of fibers (\%) for different directions and with two different amounts of fibers.

\begin{tabular}{ccccc}
\hline & & Axis Hx & Axis Hy & Axis Vz \\
\hline \multirow{2}{*}{$40 \mathrm{~kg} / \mathrm{m}^{3}$} & Specimen & 38.13 & 40.37 & 21.50 \\
& Samples & 47.70 & 34.01 & 18.29 \\
\hline \multirow{2}{*}{$60 \mathrm{~kg} / \mathrm{m}^{3}$} & Specimen & 39.65 & 36.09 & 24.25 \\
& Samples & 48.06 & 30.14 & 21.80 \\
\hline
\end{tabular}


Table 3. Measurements from each specimen by means of HP4192A analyzer uniform continuous coil taken at 7 days and 90 days.

\begin{tabular}{|c|c|c|c|c|c|c|c|c|c|}
\hline \multirow[b]{2}{*}{ Code } & \multirow[b]{2}{*}{ Specimen } & \multicolumn{4}{|c|}{$\begin{array}{c}\text { Change in inductance according to } \\
\text { measurements from } 29 / 06 / 10\end{array}$} & \multicolumn{4}{|c|}{$\begin{array}{l}\text { Change in inductance according to } \\
\text { measurements from } 8 / 09 / 10\end{array}$} \\
\hline & & $\begin{array}{c}\text { Axis } \\
\mathbf{x} \\
(\mathrm{H}) \\
\end{array}$ & $\begin{array}{c}\text { Axis } \\
\text { y } \\
(\mathrm{H})\end{array}$ & $\begin{array}{c}\text { Axis } \\
\mathrm{z} \\
(\mathrm{H})\end{array}$ & $\begin{array}{l}\text { Average } \\
\text { (H) }\end{array}$ & $\begin{array}{l}\text { Axis x } \\
\text { (H) }\end{array}$ & $\begin{array}{c}\text { Axis } \\
\mathbf{y} \\
(\mathrm{H})\end{array}$ & $\begin{array}{c}\text { Axis } \\
z \\
(\mathrm{H}) \\
\end{array}$ & $\begin{array}{l}\text { Average } \\
\text { (H) }\end{array}$ \\
\hline $30 \mathrm{~A}$ & 1 & 0.14 & 0.16 & 0.11 & 0.14 & 0.14 & 0.16 & 0.12 & 0.14 \\
\hline $30 \mathrm{~B}$ & 2 & 0.14 & 0.16 & 0.14 & 0.15 & 0.14 & 0.16 & 0.14 & 0.15 \\
\hline $31 \mathrm{~A}$ & 3 & 0.19 & 0.20 & 0.17 & 0.19 & 0.19 & 0.20 & 0.17 & 0.19 \\
\hline $31 \mathrm{~B}$ & 4 & 0.20 & 0.22 & 0.18 & 0.20 & 0.20 & 0.21 & 0.18 & 0.20 \\
\hline $32 \mathrm{~A}$ & 5 & 0.26 & 0.27 & 0.29 & 0.27 & 0.27 & 0.27 & 0.30 & 0.28 \\
\hline $32 \mathrm{~B}$ & 6 & 0.22 & 0.23 & 0.23 & 0.23 & 0.23 & 0.23 & 0.24 & 0.23 \\
\hline $33 \mathrm{~A}$ & 7 & 0.27 & 0.31 & 0.32 & 0.30 & 0.28 & 0.31 & 0.32 & 0.30 \\
\hline $33 \mathrm{~B}$ & 8 & 0.35 & 0.32 & 0.30 & 0.32 & 0.34 & 0.32 & 0.30 & 0.32 \\
\hline $34 \mathrm{~A}$ & 9 & 0.37 & 0.43 & 0.36 & 0.39 & 0.37 & 0.43 & 0.35 & 0.38 \\
\hline $34 \mathrm{~B}$ & 10 & 0.45 & 0.48 & 0.35 & 0.43 & 0.45 & 0.48 & 0.35 & 0.43 \\
\hline $35 \mathrm{~A}$ & 11 & 0.48 & 0.49 & 0.39 & 0.45 & 0.49 & 0.49 & 0.39 & 0.46 \\
\hline $35 \mathrm{~B}$ & 12 & 0.43 & 0.56 & 0.48 & 0.49 & 0.43 & 0.56 & 0.48 & 0.49 \\
\hline \multicolumn{6}{|c|}{$\begin{array}{l}\text { HP4192A analyzer and uniform } \\
\text { continuous coil }\end{array}$} & \multicolumn{4}{|c|}{ HP4192A analyzer and uniform continuous col } \\
\hline
\end{tabular}


Table 4. Results with HP4192A analyzer from the experiment with cubic specimens of SFRC compared with measured real dosage [EN 14721:2008].

\begin{tabular}{|c|c|c|c|c|c|c|c|c|}
\hline $\begin{array}{c}\text { Spe } \\
\text { cim } \\
\text { en }\end{array}$ & $\begin{array}{l}\text { Theoretic } \\
\text { al Dosage } \\
(\mathrm{kg} / \mathrm{m} 3)\end{array}$ & $\begin{array}{c}\text { Measured real } \\
\text { Dosage }(\mathrm{kg} / \mathrm{m} 3) \\
\text { EN14721:2008 }\end{array}$ & $\begin{array}{c}\text { Volum } \\
\text { e (1) }\end{array}$ & $\begin{array}{l}\text { Weigh } \\
\text { t (kg) }\end{array}$ & $\begin{array}{c}\text { Fibre } \\
\text { weigh } \\
\text { t (gr) }\end{array}$ & $\begin{array}{c}\text { Dosage } \\
(\mathrm{kg} / \mathrm{m} 3)\end{array}$ & $\begin{array}{c}\text { Dosage } \\
(\mathrm{kg} / \mathrm{m} 3)\end{array}$ & $\begin{array}{c}\text { Dosage } \\
\text { (kg/m3) }\end{array}$ \\
\hline $30 \mathrm{~A}$ & 10 & 9.94 & 3.372 & 7.514 & 33.50 & 10.18 & 9.79 & 10.24 \\
\hline $30 \mathrm{~B}$ & 10 & 11.00 & 3.364 & 7.506 & 37.00 & 10.68 & 11.02 & 11.75 \\
\hline $31 \mathrm{~A}$ & 15 & 13.51 & 3.368 & 7.469 & 45.50 & 13.55 & 13.57 & 13.76 \\
\hline $31 \mathrm{~B}$ & 15 & 14.44 & 3.360 & 7.475 & 48.50 & 14.29 & 15.05 & 15.86 \\
\hline $32 \mathrm{~A}$ & 20 & 20.14 & 3.376 & 7.585 & 68.00 & 20.37 & 20.48 & 20.40 \\
\hline $32 \mathrm{~B}$ & 20 & 16.64 & 3.395 & 7.511 & 56.50 & 17.00 & 17.27 & 17.88 \\
\hline $33 \mathrm{~A}$ & 25 & 22.90 & 3.363 & 7.460 & 77.00 & 22.09 & 22.12 & 22.49 \\
\hline 33B & 25 & 23.94 & 3.342 & 7.419 & 80.00 & 23.32 & 23.27 & 24.00 \\
\hline $34 \mathrm{~A}$ & 30 & 28.71 & 3.378 & 7.492 & 97.00 & 27.92 & 28.29 & 28.62 \\
\hline $34 \mathrm{~B}$ & 30 & 31.23 & 3.362 & 7.438 & 105.00 & 31.05 & 30.67 & 31.14 \\
\hline $35 \mathrm{~A}$ & 35 & 32.69 & 3.359 & 7.547 & 109.80 & 33.26 & 33.14 & 33.74 \\
\hline \multirow[t]{2}{*}{$35 \mathrm{~B}$} & 35 & 36.22 & 3.382 & 7.598 & 122.50 & 35.64 & 35.77 & 36.26 \\
\hline & & & & & & $\begin{array}{c}\text { Uniform } \\
\text { continuou } \\
\text { s coil }\end{array}$ & $\begin{array}{c}\text { Non- } \\
\text { uniform } \\
\text { continuou } \\
\text { s coil } \\
\end{array}$ & $\begin{array}{c}\text { Disconti } \\
\text { nuous } \\
\text { coil }\end{array}$ \\
\hline
\end{tabular}

